\section{Cranberry Evapotranspiration}

\author{
M.J. Hattendorf $\mathbf{1}^{1}$ \\ Irrigated Agriculture Research and Extension Center, Washington State \\ University, 24106 North Bunn Road, Prosser, WA 99350-9687
}

\section{J.R. Davenport ${ }^{2}$}

Ocean Spray Cranberries, One Ocean Spray Drive, Lakeville-Middleboro, MA 02349

Additional index words. Vaccinium macrocarpon, canopy temperature, water use, stomatal conductance, reference evapotranspiration

\begin{abstract}
Cranberry (Vaccinium macrocarpon Ait.) evapotranspiration (ET) has not been documented. Micrometeorological techniques based on canopy temperature minus air temperature were used to estimate ET on 'Stevens' and 'Crowley' cranberry at Long Beach (lat. $\approx 46^{\circ} 20^{\prime} \mathrm{N}$, long. $124^{\circ} \mathrm{W}$ ) and Grayland (lat. $\approx 46^{\circ} 47^{\prime} \mathrm{N}$, long. $124^{\circ} \mathrm{W}$ ), Wash., in 1991 and 1992, respectively. Cranberry ET was 55\% of Priestley-Taylor reference ET and ranged from $<0.5$ to $>4 \mathrm{~mm} \cdot \mathrm{d}^{-1}$. The Priestley-Taylor reference ET was a very good predictor of cranberry ET $\left(r^{2}=0.795\right)$. Running 7-day cumulative ET ranged from 7 to 17 mm. week $^{-1}$.
\end{abstract}

Estimates of cranberry evapotranspiration (ET) are fundamental for developing irrigation scheduling that is based on actual crop water use. Current "rule of thumb" on the Washington coast for irrigation applications (Shawa et al., 1984) is $25 \mathrm{~mm} \cdot$ week $^{-1}$, but there are no cranberry ET data to support this practice. Crops of somewhat similar stature, such as turfgrasses, had daily maximum ET rates ranging from 5.5 to $7.7 \mathrm{~mm} \cdot \mathrm{d}^{-1}$ (Fernandez and Love, 1993). The ET rates of several Cynodon genotypes ranged from 4.2 to $5.2 \mathrm{~mm} \cdot \mathrm{d}^{-1}$ under field conditions (Beard et al., 1992). Irrigation recommendations based on evaporative demand would better reflect changing daily and seasonal weather conditions. It is desirable to refine existing irrigation practices to prevent movement of chemicals or nutrients out of the crop rooting zone in the sensitive wetland areas in which cranberry grows. The first step in this process is to obtain ET estimates for cranberry experimentally.

Canopy-temperature-based energy balance methods for estimating ET have proven reliable in past studies (Choudhury et al., 1986; Hatfield et al., 1984; Kalma and Jupp, 1990). Cranberry is well-suited to a canopy-

Received for publication 6 Dec. 1995. Accepted for publication 7 Feb. 1996. Washington State Univ. Agriculture Research Center Paper no. 9412-33. This research was supported by grants from Ocean Spray Cranberries and U.S. Dept. of AgricultureAgricultural Research Service (USDA-ARS). We thank Frank O. Glenn, III, and Nick Woods, growers, for allowing access to their cranberry bogs, and Kim Patten, Washington State Univ.-Long Beach, and Andy Broaddus, Ocean Spray, Markham, Wash., for their cooperation. We also thank USDA-ARS, Prosser, Wash., for use of laboratory space and vehicle loans. Use of trade names does not imply endorsement of the products named by Washington State Univ. or Ocean Spray Cranberries. The cost of publishing this paper was defrayed in part by the payment of page charges. Under postal regulations, this paper therefore must be hereby marked advertisement solely to indicate this fact.

${ }^{1}$ Research Associate.

${ }^{2}$ Manager, Agricultural Research. temperature-based technique because it is a perennial crop that retains a leaf canopy yearround, but sheds older leaves after $\approx 18$ months. Dormancy is manifest by a change of leaf color from green (growing) to dull red (dormant). The short, spreading, carpet-like canopy is typically $\approx 0.15 \mathrm{~m}$ in height.

To make daily crop ET estimates from easily obtained data, the experimentally determined ET values must be related to some reference value. A commonly used reference value for ET estimation is the reference ET from a "standard" crop such as grass or alfalfa (Medicago sativa L.). The meteorological data can be obtained from standard weather station data.

The objectives of this study were to experimentally obtain estimates of cranberry ET and relate cranberry ET to the reference ET.

\section{Materials and Methods}

Instrumentation was sited on bogs owned by growers near Long Beach and Grayland, Wash. The Long Beach bog, established around 1983 , was $\approx 100 \times 200 \mathrm{~m}$ (east-west and northsouth dimensions, respectively) and planted to 'Stevens' cranberry. The Grayland bog $(250 \times$ $70 \mathrm{~m}$ ) was planted to a random mixture of 'Stevens' and 'Crowley' cranberry in 1986. Both bogs were $\approx 1 \mathrm{~km}$ from the ocean. The plantings were mature and had complete canopy cover.

The soil type at Long Beach was a seastrand muck (sandy-skeletal, mixed, dysic mesictypic medihemists) overlaid by 0.15 to $0.2 \mathrm{~m}$ of sand and interspersed at the top with organic matter from leaf understory decay. The soil at Grayland was an orcas peat (dysic, mesic Typic Sphagnofibrists) that had never been sanded. Both soils were well-drained and wellaerated but kept moist by rainfall or irrigation. Herbicides and insecticides were applied when necessary during the growing season.

Instrumentation used in the energy balance equation for cranberry ET estimates included three infrared temperature sensors (Everest
Interscience, Fullerton, Calif.) and a net radiometer (Radiation Energy Balance Systems Q*6, Bothell, Wash.), which were mounted at $\approx 1$ - $\mathrm{m}$ height and were placed $20 \mathrm{~m}$ into the bogs to avoid border effects. Anemometers were mounted at the $0.38-\mathrm{m}$ height at Long Beach and at Grayland to achieve 1:50 fetch (instrument height to field-border distance) in all directions. Air temperature and relative humidity sensors with 12-plate Gill radiation shields were placed at the 0.38 -m height (model HMP35C; Vaisala, Woburn, Mass.). All instrumentation was connected to a base weather station, which included a Campbell Scientific CR10 datalogger and SC12 modem (Campbell Scientific, Logan, Utah), scanned at 10-s intervals, and averaged or totaled every $30 \mathrm{~min}$. Data were retrieved by phone modem nearly daily during the growing season. Field instrument checks were made every 2 to 3 weeks in the growing season. Instruments were calibrated at the end of each growing season. Instrument drift was minimal.

Energy balance equations take the general form of

$\mathrm{RN}-\mathrm{G}=\mathrm{SH}+\mathrm{LE}$,

where RN is net radiation, $\mathrm{G}$ is soil heat flux, $\mathrm{SH}$ is sensible heat flux, and LE is latent energy flux, or ET. In expanded form, the equation is

$R N-G=\rho \frac{C_{p}}{r_{a}}(T s-T a)+\rho C_{p} \frac{R N}{\Gamma} \cdot \frac{\left(e_{s} T s-e_{s} T a\right)}{\left(r_{c}+r_{a}\right)[2]}$

where $r_{a}=$ aerodynamic resistance to sensible heat transport $\left(\mathrm{s} \cdot \mathrm{m}^{-1}\right)$ and

$r_{a}=\frac{\left[\frac{\ln (z-d)}{z 0}\right]^{2}}{k^{2} u} \cdot\left[1-n(z-d) g \frac{(T s-T a)}{T u^{2}}\right]$ [3]

In the equations, $\mathrm{s}=$ seconds, $\mathrm{z}=$ instrument height $(\mathrm{m}), \mathrm{d}=$ zero plane displacement $(\mathrm{m})$, $\mathrm{z} 0=$ roughness length $(\mathrm{m}), \mathrm{u}=$ wind speed $\left(\mathrm{m} \cdot \mathrm{s}^{-1}\right), \mathrm{k}$ is von Karman's constant $(0.41), \mathrm{n}=$ stability factor $(\mathrm{n}=4$ in unstable lapse conditions, $\mathrm{n}=5$ in stable and neutral lapse conditions) (Monteith and Unsworth, 1990), g = acceleration of gravity $\left(\mathrm{m} \cdot \mathrm{s}^{-2}\right), \mathrm{T}=$ mean of Ts and $\mathrm{Ta}(\mathrm{K}), \mathrm{r}_{\mathrm{c}}=$ crop resistance to vapor transport $\left(\mathrm{s} \cdot \mathrm{m}^{-1}\right), \mathrm{Ts}=$ crop surface temperature $\left({ }^{\circ} \mathrm{C}\right), \mathrm{Ta}=$ air temperature $\left({ }^{\circ} \mathrm{C}\right), \rho=$ air density $\left(\mathrm{kg} \cdot \mathrm{m}^{-3}\right), \mathrm{C}_{\mathrm{p}}=$ specific heat at constant pressure $\left(\mathrm{J} \cdot \mathrm{K}^{-1} \cdot \mathrm{kg}^{-1}\right), \Gamma=$ psychrometric constant $\left(\mathrm{kPa} \cdot \mathrm{C}^{-1}\right), \mathrm{e}_{\mathrm{s}} \mathrm{Ta}=$ saturated vapor pressure at $\mathrm{Ts}(\mathrm{kPa}), \mathrm{e}_{\mathrm{a}} \mathrm{Ta}=$ saturated vapor pressure at $\mathrm{Ta}(\mathrm{kPa})$. Cranberry ET was calculated by rearranging the equation to solve for LE (second term on the right of Eqs. [1] and [2]). Conditions necessary to the success of this method are 1) at least a 1:50 fetch to the instruments; 2) complete canopy cover; and 3) the assumption that the roughness lengths of momentum, heat, and vapor transfer from the crop canopy are equal. This assumption was considered valid because the cranberry canopy was very short, was held almost entirely at the upper canopy surface, and there was little penetration of light or wind below the surface layer of the canopy. Stability conditions were assessed by the difference between $\mathrm{Ts}$ and $\mathrm{Ta}$ 
at the canopy surface and the $0.38-\mathrm{m}$ instrument height, respectively.

The energy balance calculation to estimate cranberry ET assumed $\mathrm{d}=0.80 *$ crop height and $\mathrm{z} 0=0.05^{*}$ crop height (Hatfield et al., 1984). These values were used because of the relative smoothness of the cranberry canopy. Because cranberry is very short and spreading with a dense mat of small leaves, the surface is comparatively smooth. Crop height was 0.15 $\mathrm{m}$ and varied little during the growing season. Dew accumulation and evaporation were estimated and subtracted from the cranberry ET calculations (Pedro and Gillespie, 1982). Because of the coolness of the coastal climate, dewfall occurred nearly every night (according to calculations using the energy balance equation) and often persisted until 1000 or 1030 HR each morning. While dew was on the leaves, transpiration was assumed to be zero.

Weather stations were placed in the southwest corner of the bog at Long Beach and on the south side of a bog at Grayland. Instrumentation on these weather stations included a pyranometer (model 200S; LI-COR, Lincoln, Neb.), air temperature and relative humidity sensor (model HMP35C; Vaisala, Woburn, Mass.), an anemometer and wind vane (Wind Sentry, RM Young Co., Traverse City, Mich.), a tipping bucket rain gauge (TE525; Texas Electronics, Dallas), and a soil temperature thermistor (Campbell Scientific). The anemometer, wind vane, and pyranometer were placed $3 \mathrm{~m}$ above the surface. The air temperature and relative humidity sensor was placed at $2 \mathrm{~m}$ above the surface and shielded with a 12plate Gill radiation shield. Soil temperature was measured at the $0.05-\mathrm{m}$ depth. At Long Beach, the tipping bucket rain gauge was placed $10 \mathrm{~m}$ into the bog, which allowed measurement of rainfall and irrigation within the bog. At Grayland, the tipping bucket rain gauge was placed adjacent to the weather station. Data from these stations were used in the reference ET calculation.

The Priestley-Taylor reference ET equation was used to estimate evaporative demand from the 2-m height instrumentation. Steiner et al. (1991) showed that the Priestley-Taylor equation could be used successfully to calculate reference ET. Several attempts were made to use Penman-type reference ET with various wind functions, such as the Kimberly wind function coefficients, the original Penman coefficients, and the CIMIS Penman equation (R. Snyder, Univ. of California, Davis, personal communication). Estimated Penman reference ET often exceeded $15 \mathrm{~mm} \cdot \mathrm{d}^{-1}$ and the Priestley-Taylor equation was used to avoid reliance on empirical wind functions.

The Priestley-Taylor reference ET =

$\mathrm{ET}=\frac{\left(\alpha^{\prime} \cdot \mathrm{s}\right)}{(\mathrm{s} \cdot \Gamma)} \cdot(\mathrm{RN}-\mathrm{G})$,

where $s$ is the slope of the saturated vapor pressure-temperature curve. The terms RN, G, and $\Gamma$ were previously defined. The PriestleyTaylor equation has no wind speed component, but has an "alpha" $\left(\alpha^{\prime}\right)$ factor that was adjusted for vapor pressure deficit (VPD, $\mathrm{kPa}$ ): $\alpha^{\prime}=1+0.26^{*}$ VPD (Steiner et al., 1991). In this manuscript, net radiation over grass was estimated using methods of Dong et al. (1992), who used data from weather stations from several climate zones in California for validation, making the reference ET value a grass reference rather than an alfalfa reference. Solar altitude and zenith angle were calculated using equations in Hodges and Evans (1990).

On 10 Sept. 1991, stomatal conductance was measured at the Long Beach bog with a LI-COR 1600 porometer fitted with a $250-\mathrm{ml}$ chamber. Stomatal conductance data were collected at $1125,1400,1500$, and $1600 \mathrm{HR}$ on three replications of 20 tagged stems. Stems were tagged so that the same leaves were enclosed in the chamber each time. At the end of the day, the individual stems were severed at the tag and transported in humid plastic bags to a leaf area meter. One-sided leaf area was then measured cumulatively for each stem. These leaf area values were used to correct the stomatal conductance values for true leaf area. The porometer chamber was oriented so that no shadows fell in the chamber during measurement.

\section{Results and Discussion}

Estimated total seasonal reference ET and cranberry ET were less in 1991 than in 1992 at Long Beach. Reference ET in 1991 and 1992 was 318 and $440 \mathrm{~mm}$, respectively. Estimated cranberry ET was 186 and $245 \mathrm{~mm}$ in 1991 and 1992 , respectively. Greater total net radiation in $1992\left(1052 \mathrm{MJ} \cdot \mathrm{m}^{-2}\right)$ accounted for the yearto-year differences in reference ET. Total net radiation in 1992 was 10\% higher than in 1991 from days 133 to 176 . Net radiation is the main driving variable in the Priestley-Taylor reference ET equation and in the cranberry energy balance calculations.

Cranberry ET was quite low compared to reference ET. Regression analysis of estimated ET on the Priestley-Taylor reference ET indicated that cranberry ET was $\approx 55 \%$ of the reference ET (Fig. 1). Differences in ET by cultivar or location were not discernible. Because the regression equation with combined years was so similar, only the 1992 data are shown for clarity. The ratio of calculated cranberry ET : reference ET was low in comparison to maximum crop coefficients of alfalfa (>1.0) (Sammis et al., 1985) and highly managed golf course turf (0.80) (Devitt et al. 1992); however, low-management turf had a maximum crop coefficient of 0.60

Cranberry has small, waxy leaves with stomata only on the abaxial side of the leaves. The stomata are structured as slits and seem to have weak responses to environmental stimuli (Faraq and Palta, 1989; Sawyer, 1932), despite having many stomata per area (average 632 stomata/mm) (Sawyer, 1932).

Stomatal conductance of cranberry was measured at Long Beach on 10 Sept. 1991 to attempt to explain why cranberry ET was comparatively low. Daytime conditions were clear and warm $\left(>20{ }^{\circ} \mathrm{C}\right)$, except during the $1500 \mathrm{HR}$ measurements, when a thick fog bank came in from offshore, and at one point, reduced photosynthetically active radiation
$(P A R)$ to about one-tenth of its highest clear sky value, which was $2060 \mu \mathrm{mol} \cdot \mathrm{m}^{-2} \cdot \mathrm{s}^{-1}$. The mean Long Beach stomatal conductances were $0.001 \mathrm{~m} \cdot \mathrm{s}^{-1}$ with standard deviations of 0.0002 $\mathrm{m} \cdot \mathrm{s}^{-1}$ at all times of the day and all $P A R$ values. Mean $P A R$ ranged from $811 \mu \mathrm{mol} \cdot \mathrm{m}^{-2} \cdot \mathrm{s}^{-1}$ at $1500 \mathrm{HR}$ to $1720 \mu \mathrm{mol} \cdot \mathrm{m}^{-2} \cdot \mathrm{s}^{-1}$ at $1125 \mathrm{HR}$. The stomatal conductance values were an order of magnitude higher than those of Croft et al. (1993), who reported mean stomatal conductance of $0.00044 \mathrm{~m} \cdot \mathrm{s}^{-1}$ under clear sky conditions. In a subsequent report (Croft and Vorsa, 1993), the authors suggested that the values in Croft et al. (1993) represented stomatal conductances of cranberries experiencing water stress under field conditions. Other typical crop or native species stomatal conductances ranged from $0.02 \mathrm{~m} \cdot \mathrm{s}^{-1}$ for alfalfa in Minnesota (Carter and Scheaffer, 1983) and $\approx 0.009$ $\mathrm{m} \cdot \mathrm{s}^{-1}$ for Populus clones (Ceulemans et al., 1988). Nobel and Jordan (1983) found stomatal conductances ranging from $0.014 \mathrm{~m} \cdot \mathrm{s}^{-1}$ for the C3 plant Encelia farinosa Gray, 0.009 $\mathrm{m} \cdot \mathrm{s}^{-1}$ for the $\mathrm{C} 4$ bunchgrass Hilaria rigida Benth., and $0.002 \mathrm{~m} \cdot \mathrm{s}^{-1}$ for the CAM plant Agave deserti Engelm. Cranberry stomatal conductance from this study most closely resembled the stomatal conductance of the CAM plant agave, and is at the low end of Nobel's list of representative values for crop stomatal conductance (Nobel, 1983). Cranberry leaf and stomatal characteristics resembled those of xeromorphic plants whose leaves are structured to limit water loss. The low stomatal conductance values found by us and by Croft et al. (1993) help explain the comparatively low ratio of cranberry ET to reference ET. The stomatal conductance data from our study also illustrated an apparent insensitivity of cranberry stomates to decreased solar radiation, as at $1500 \mathrm{HR}$. No significant change in stomatal conductance was detected with a $47 \%$ drop in mean $P A R$ (from 1720 to $811 \mu \mathrm{mol} \cdot \mathrm{m}^{-2} \cdot \mathrm{s}^{-1}$ ). According to Hagidimitriou (1993), cranberry light saturation for photosynthesis occurred in the field between 900 to $1000 \mu \mathrm{mol} \cdot \mathrm{m}^{-2} \cdot \mathrm{s}^{-1}$. Light saturation at these values may help explain why cranberry stomatal conductance showed little response to large reductions in $P A R$. Croft et al. (1993) also indicated that cranberry stomatal conductance showed limited and relatively slow response to changing environmental conditions. While 1 day of data (from this study) does not necessarily characterize the entire stomatal response of cranberry, it is still indicative of stomatal response to full sunlight, moderate temperatures, and moist soil. Some consistency of response would be expected from day to day under similar conditions. The sources cited support our data and conclusions about cranberry stomatal conductance.

Reference ET methods should, theoretically, be able to transcend climate differences to be relevant in other locations. The PriestleyTaylor equation with an alpha modification for VPD was chosen because it had proven effective in disparate climates and had simpler requirements than Penman-type equations (Steiner et al., 1991). While reliant on the alpha value, which is an empirical value, the 


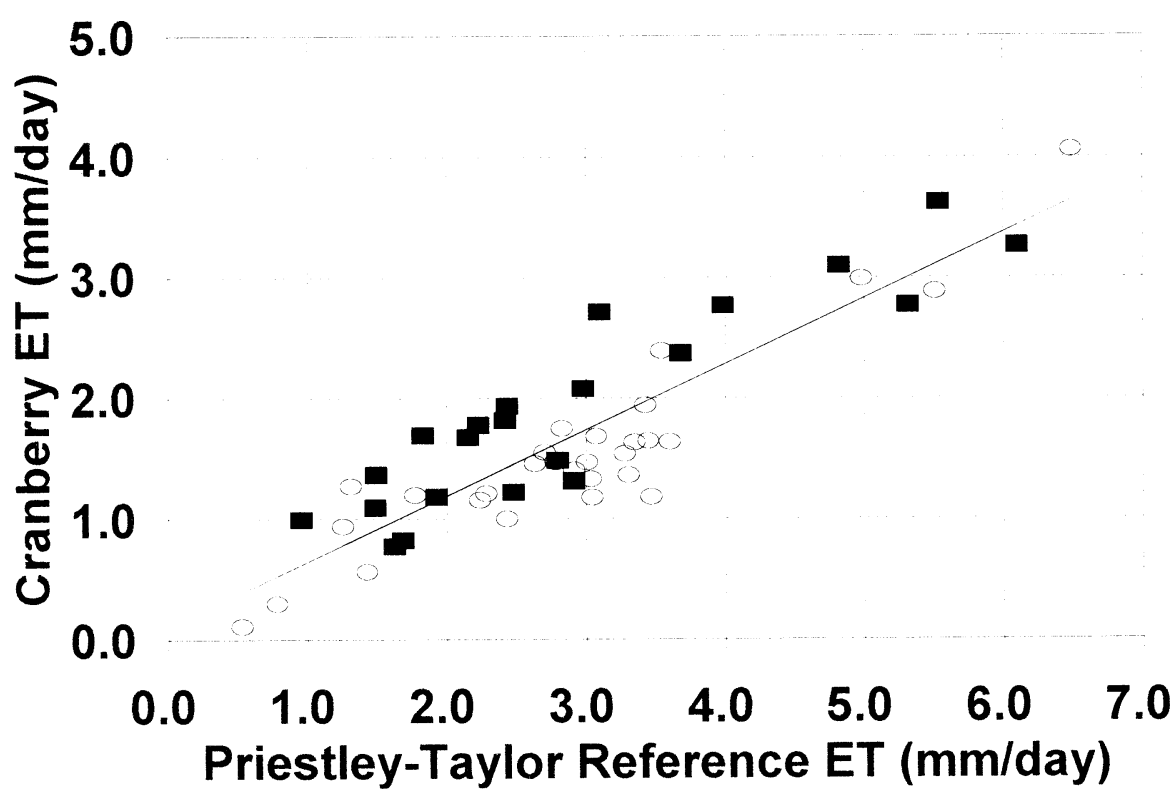

Fig. 1. Regression of cranberry evapotranspiration (ET) on Priestley-Taylor reference ET (ETR) in 1992 at $(\mathbf{\square})$ Grayland and $(\mathrm{O})$ Long Beach. ET $=0.10+0.55^{*}(\mathrm{ETR})$, with $r^{2}=0.795, \mathrm{n}=51$.

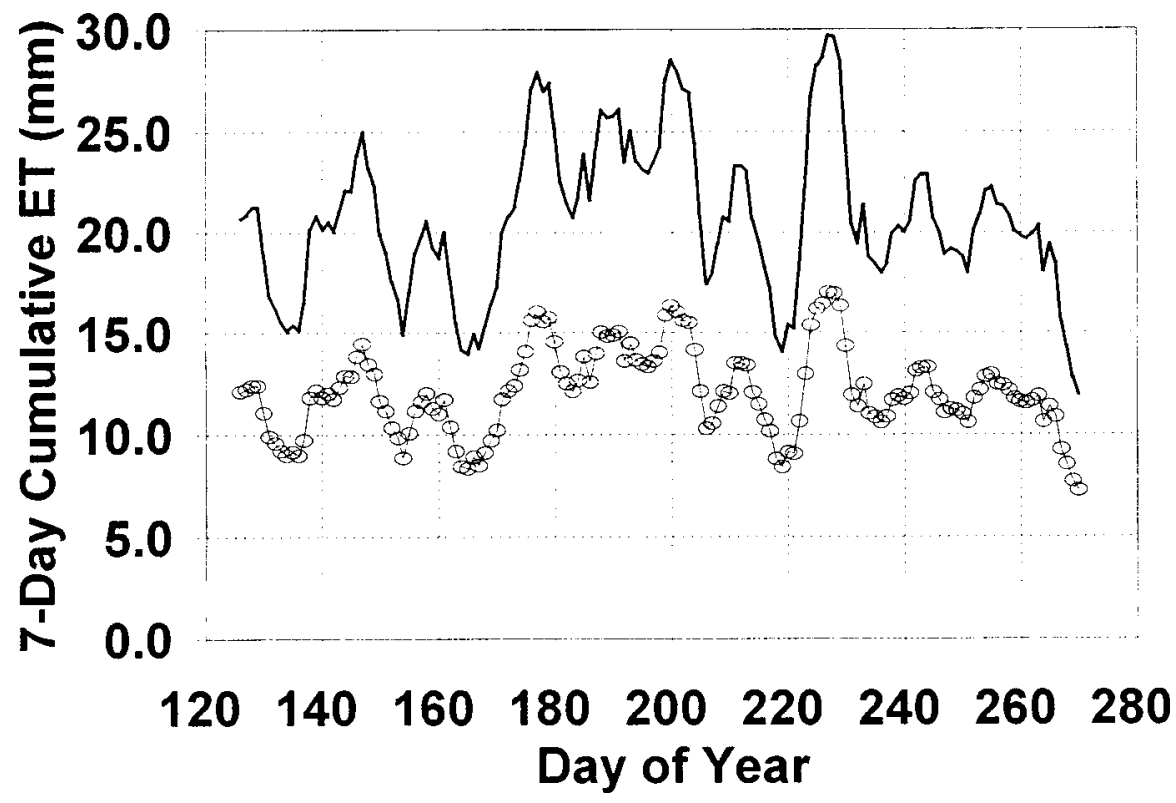

Fig. 2. Seven-day cumulative cranberry evapotranspiration (ET) (-O-) and reference ET (-) at Long Beach, 1992. Sums were calculated by adding daily ET through days 1-7, 2-8, etc.

Priestley-Taylor equation usually gave values of reference ET $<5 \mathrm{~mm} \cdot \mathrm{d}^{-1}$, which were consistent with the cool, humid coastal climate (Fig. 1). As a comparison, mean daily PriestleyTaylor reference ET at Forest Grove, Ore. (30 km west of Portland, Ore., $120 \mathrm{~km}$ southeast of Long Beach, Wash., elevation $6 \mathrm{~m}$ ) from 1976 to 1980 was $3.5 \mathrm{~mm} \cdot \mathrm{d}^{-1}$ from March or April through September (Hill et al., 1983). Mean daily ET at Willapa Harbor (lat. $46^{\circ} 41^{\prime} \mathrm{N}$, long. $\left.123^{\circ} 07^{\top} \mathrm{W}\right)$ from April through September (1931-60) was $2.4 \mathrm{~mm} \cdot \mathrm{d}^{-1}$ (Philips and Donaldson, 1972). Mean daily PriestleyTaylor reference ET at Kimberley, Idaho, from 1 Apr. to 31 Oct. (1976-80) was $4.0 \mathrm{~mm} \cdot \mathrm{d}^{-1}$ (Hill et al., 1983). At Long Beach in 1992, mean daily reference ET from May through September was $2.9 \mathrm{~mm} \cdot \mathrm{d}^{-1}$. ences in cranberry ET between locations or cultivars were evident. Stomatal conductance values from this study were in substantial agreement with cranberry stomatal conductance values from other studies.

\section{Literature Cited}

Beard, J.B., R.L. Green, and S.I. Sifers. 1992. Evapotranspiration and leaf extension rates of 24 wellwatered, turf-type Cynodon genotypes. HortScience 27:986-988.

Carter, P.R. and C.C. Sheaffer. 1983. Alfalfa response to soil water deficits. II. Plant water potential, leaf conductance, and canopy temperature relationships. Crop Sci. 23:676-680.

Ceulemans, R., I. Impens, and R. Imler. 1988. Stomatal conductance and stomatal behavior in Populus clones and hybrids. Can. J. Bot. 66:1404-1414.

Choudhury, B.J., R.J. Reginato, and S.B. Idso. 1986. An analysis of infrared temperature observations over wheat and calculation of latent heat flux. Agr. \& For. Meteorol. 37:75-88.

Croft, P.J., M.D. Shulman, and R. Avisson. 1993. Cranberry stomatal conductivity. HortScience 28:1114-1116.

Croft , P.J. and N. Vorsa. 1993. Cranberry stomatal conductivity as related to rainfall amount and frequency. 21st Conf. on Agr. and For. Meteorol. and 11th Conf. on Biometeorology and Aerobiology, San Diego, 7-11 Mar. 1994. p. 340-341.

Devitt, D.A., R.L. Morris, and D.C. Bowman. 1992. Evapotransportation [sic], crop coefficients, and leaching fractions of irrigated desert turfgrass systems. Agron. J. 84:717-723.

Dong, A., S.R. Grattan, J.J. Carroll, and C.R.K. Prashar. 1992. Estimation of daytime net radiation over well-watered grass. J. Irr. \& Drain. Eng. (Amer. Soc. Civil Eng.) 118:466-479.

Faraq, K.M. and J.P. Palta. 1989. Ultrastructure and surface morphology of cranberry plant with reference to ethrel penetration. Acta Hort. 4th Intl. Symp. Vaccinium Cult., Lansing, Mich., 13-17 Aug. 1988. p. 378-384.

Fernandez, G.C.J. and B. Love. 1993. Comparing turfgrass cumulative evapotranspiration curves. HortScience 28:732-734.

Hagidimitriou, M. 1993. Carbohydrate partitioning and photosynthesis in cranberry (Vaccinium macrocarpon Ait.). PhD Diss., Univ. of Wisconsin-Madison.

Hatfield,J.L., R.J.Reginato, and S.B.Idso. 1984.Evaluation of canopy temperature-evapotranspiration models over various crops. Agr. \& For. Meteorol. 32:41-53.

Hill, R.W., E.L. Johns, and D.K. Frevert. 1983. Comparison of equations used for estimating agricultural crop evapotranspiration with field research. Tech. Rpt., Bureau of Reclamation, U.S. Dept. of the Interior, Washington, D.C.

Hodges, T. and D.W. Evans. 1990. Light interception model for estimating the effects of row spacing on plant competition in maize. J. Production Agr. 3:190-195.

Kalma, J.D. and D.L.B. Jupp. 1990. Estimating evapotranspiration from pasture using infrared thermometry: Evaluation of a one-layer resistance model. Agr. \& For. Meteorol. 51:223296.

Monteith, J.L. and M.H. Unsworth. 1990. Principles of environmental physics. Edward Arnold, London.

Nobel, P.S. 1983. Biophysical plant physiology and ecology. W.H. Freeman, San Francisco.

Nobel, P.S. and P.W. Jordan. 1983. Transpiration streams of desert species: Resistances and capacitances for a C3, a C4, and a CAM plant. J. 
Expt. Bot. 34:1379-1381.

Pedro, M.J., Jr., and T.J. Gillespie. 1982. Estimating dew duration. I. Utilizing micrometeorological data. Agr. Meteorol. 25:283-296.

Philips, E.L. and W.R. Donaldson. 1972. Washington climate for these counties: Clallum, Grays Harbor, Jefferson, Pacific, and Wahkiakum. EM 3708, Coop. Ext. Serv., Washington State Univ. and U.S. Dept. Agr., Pullman.
Sammis, T.W., C.L. Mapel, D.G. Lugg, R.R. Lansford, and J.T. McGuckin. 1985. Evapotranspiration crop coefficients predicted using growing degree-days. Trans. Amer. Soc. Agr. Eng. 28:773-780.

Sawyer, W.H. 1932. Stomatal apparatus of the cultivated cranberry, Vaccinium macrocarpon. Amer. J. Bot. 19:508-513.

Shawa, A.Y., C.H. Shanks, Jr., P.R. Bristow, M.N.
Shearer, and A.P. Poole. 1984. Cranberry production in the Pacific Northwest. Pacific NorthWest 247, Coop. Ext., Washington State Univ., Oregon State Univ., and U.S. Dept. Agr.Agr. Res. Serv.

Steiner, J.L., T.A. Howell, and A.D. Schneider 1991. Lysimetric evaluation of daily potential evapotranspiration models for grain sorghum. Agron. J. 83:240-247. 